\title{
Avaliação de geomorfosítios e valorização de turfeiras de planalto no Parque Estadual da Serra do Tabuleiro-SC
}

\author{
Marcelo Accioly Teixeira de Oliveira ${ }^{*}$ \\ Gisele Leite de Lima**
}

\section{Resumo}

A avaliação de geomorfosítios permite atribuição de valor a unidades específicas do relevo e sua aplicação em unidades de conservação brasileiras abre espaço para a Geomorfologia no campo da definição e da preservação do patrimônio natural. Entretanto, o conceito de geomorfosítio transcende a visão preservacionista clássica, centrada no monumental, abrindo perspectivas para a aplicação da Geomorfologia no campo do planejamento e da gestão territorial. Neste trabalho, adotamos metodologia de avaliação de geomorfosítios para a valoração de turfeiras de planalto no Parque Estadual da Serra do Tabuleiro. Os resultados obtidos demonstram a aplicabilidade do método ao problema da definição de espaços protegidos e introduz discussão sobre a formação de profissionais em geomorfologia e sobre sua contribuição para a resolução de problemas que derivam da relação entre a sociedade e a natureza no Brasil.

Palavras-chave: Geomorfosítio; Turfeira; Recursos naturais.

* Departamento de Geociências, CFH/UFSC (maroliv@cfh.ufsc.br).

** Programa de Pós-Graduação em Geografia, Departamento de Geociências, CFH/UFSC (glima5@yahoo.com).

Geosul, Florianópolis, v. 23, n. 46, p 137-162, jul./dez. 2008 
OLIVEIRA, M.A.T. de \& LIMA, G.L. de. Avaliação de geomorfosítios e ...

Geomorphosite evaluation and upland peat valorization in the

Santa Catarina state's "Serra do Tabuleiro" Park

\begin{abstract}
The evaluation of geomophosites enables attribution of value for specific landforms. Its application to Brazilian protected areas opens to Geomorphology a field of activity related with natural and geological heritages. However, as the concept of geomorphosite implies both the protection of natural environments and the optimization of landforms for different uses, their evaluation process transcends the classical notion of natural heritage, centered in the wilderness concept, also opening to Geomorphology application on territorial management. This paper adopt a method for geomorphosite evaluation in order to assess upland peat bogs in the Santa Catarina State's "Serra do Tabuleiro" Park. Results show the applicability of the method to the problem of protected areas and introduce discussion about the backgrounds of geomorphological education and the ability of geomorphologists to contribute solving natural and social problems in Brazil.
\end{abstract}

Key words: Geomorphosite; Peat; Natural assets.

\title{
Introdução
}

O Sistema Nacional de Unidades de Conservação da Natureza (SNUC) prevê, em seu artigo $4^{\circ}$, que locais com características geomorfológicas relevantes devam ser protegidos e ressaltados no interior de unidades de conservação (Brasil, 2000). Apesar dessa previsão de natureza legal, estudos geomorfológicos aplicados a unidades de conservação (UC) brasileiras são raros.

Várias causas podem ser propostas para a relativa ausência da aplicação de estudos geomorfológicos em unidades de conservação brasileiras (história do conservacionismo; atuação de instituições internacionais para a proteção ambiental; ênfase na biodiversidade; desinteresse acadêmico, etc.). Resta que, em função dessa ausência, a delimitação e o planejamento de áreas 
OLIVEIRA, M.A.T. de \& LIMA, G.L. de. Avaliação de geomorfosítios e ...

protegidas têm sido feitos, sobretudo, em função de critérios bióticos. Embora fundamentais, quando utilizados exclusivamente, os critérios bióticos podem levar à negligência de fatores abióticos que são igualmente importantes (RANDOLPH \& BESSA, 1993). Dentre os possíveis fatores abióticos, destaca-se o relevo, que constitui importante substrato e interface de agentes múltiplos, de origem física e biológica (REYNARD \& PANIZZA, 2005). Neste trabalho, sintetizamos resultados preliminares de pesquisas geomorfológicas em curso no Parque Estadual da Serra do Tabuleiro, maior unidade de conservação do Estado de Santa Catarina, através da aplicação de abordagem desenvolvida para a valorização e para a avaliação dos chamados geomorfosítios.

Geomorfosítios são genericamente definidos como formas de relevo, de dimensões variadas, às quais pode ser atribuído valor, em função de motivos científicos, culturais, estéticos e/ou sócioeconômicos (PANIZZA, 2001). De modo mais restrito, geomorfosítios também podem ser definidos como objetos geomorfológicos que contribuam para a compreensão e para a reconstituição da história da Terra (REYNARD, 2005), sendo considerados, nesse caso, como objetos de natureza eminentemente científica e educacional. Em ambos os casos, a definição de critérios para a atribuição de valor às formas de relevo é fundamental.

De modo a compatibilizar as definições acima, geral e restrita, Reynard (2005) sugere a adoção de dois níveis distintos de valoração de sítios geomorfológicos: no primeiro nível, considerado central, é dada ênfase ao valor científico do sítio; no segundo nível, considerado complementar, leva-se em consideração as demais formas de valorização (estética, ecológica, cultural e econômica), que seriam incorporadas em função da finalidade do trabalho.

Conseqüentemente, percebe-se que o conceito de geomorfosítio introduz abordagem de valoração de sítios geológicos e geomorfológicos que tende a transcender o modelo de valorização de espaços naturais herdado da filosofia de criação de Parques Nacionais nos Estados Unidos da América, no século XIX. 
OLIVEIRA, M.A.T. de \& LIMA, G.L. de. Avaliação de geomorfosítios e ...

Esse modelo, voltado para a proteção da vida selvagem e da "paisagem agreste" (wilderness), conceito intimamente relacionado à percepção de espaços selvagens, não modificados pela humanidade, é o mesmo que inspira a legislação brasileira para áreas de proteção ambiental (DIEGUES, 1996). Esse é o modelo que fundamenta, igualmente, a definição de "monumentos naturais", tal como proposto pela Declaração Internacional dos Direitos à Memória da Terra (UNESCO, 1991). A abordagem introduzida pela discussão sobre geomorfosítios acrescenta ao critério estético clássico de valorização (fundamentado na paisagem e no monumental) uma concepção de proteção e de uso que deriva, sobretudo, da avaliação ampla do caráter científico do sítio escolhido. Através da ênfase dada às formas de relevo como interfaces de agentes múltiplos se privilegia, de fato, abordagem que é centrada na dinâmica dos processos geomorfológicos e no reconhecimento de geomorfosítios como locais privilegiados para o estudo e para a compreensão da história da Terra latu sensu, nela incluindo-se a história da vida, dos seres humanos e de suas sociedades (REYNARD, 2005). Nesse sentido, geomorfosítios seriam formas de relevo cujo valor específico é o principal fator a partir do qual seriam determinadas opções e estratégias de proteção, assim como de utilização dos recursos naturais, fundamentadas em critérios de avaliação abiótica que fazem parte do domínio da Geomorfologia.

\section{Área de estudo}

O Parque Estadual da Serra do Tabuleiro (PEST) é a maior unidade de conservação do Estado de Santa Catarina, ocupando 87.405 hectares de ilhas, cordões litorâneos, manguezais, encostas e montanhas, e cobrindo área equivalente a aproximadamente $1 \%$ do território do Estado (Figura 1). Sua criação data de 1975 e foi efetuada através do decreto $\mathrm{n}^{\circ} 1.260 / 75$, abarcando áreas dos territórios de nove municípios nas proximidades de Florianópolis. 
OLIVEIRA, M.A.T. de \& LIMA, G.L. de. Avaliação de geomorfosítios e ...

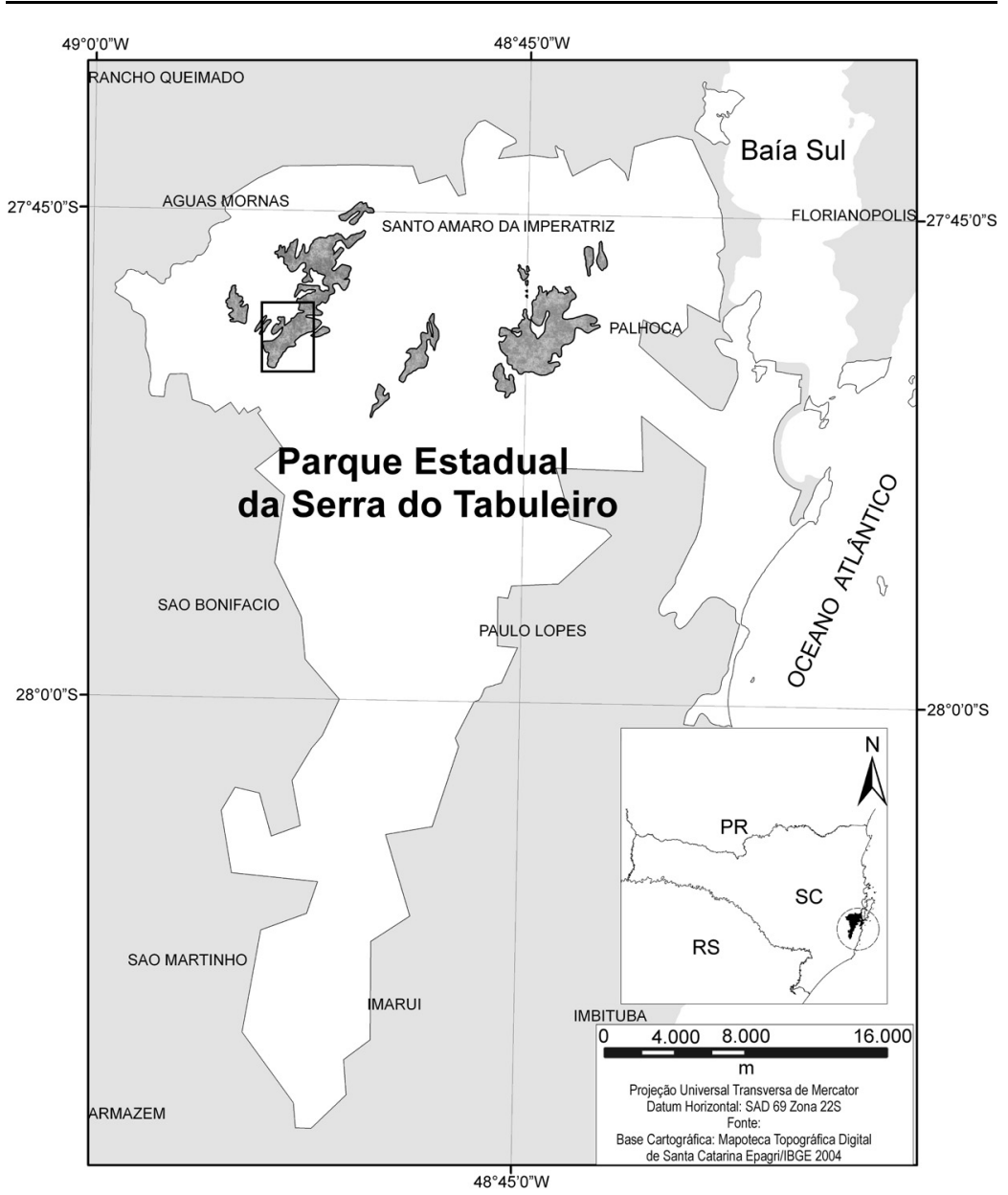

Figura 1: Área de estudo. As áreas ressaltadas por textura em tons de cinza no interior do parque, indicam seus principais "tabuleiros", ou chapadões. O retângulo ao Sul de um desses chapadões indica o local específico do estudo (ver Figura 3). 
OLIVEIRA, M.A.T. de \& LIMA, G.L. de. Avaliação de geomorfosítios e ...

O parque reúne cinco das seis composições vegetais que ocorrem no Estado de Santa Catarina, passando, do litoral para os planaltos de topo, pelas vegetações de Restinga; Floresta Pluvial da Encosta Atlântica; Matinha Nebular; Pinhais e Campos de Altitude. Seu setor continental é caracterizado por ambiente montanhoso de rara beleza cênica, no qual têm origem córregos que alimentam os rios Vargem do Braço e Cubatão, cujas águas abastecem a população da chamada Grande Florianópolis. As águas dos rios Vargem do Braço e Cubatão surgem, primeiramente, em nascentes nas cabeceiras de topo dos planaltos do parque, em altitudes que variam de 900 a 1.260 metros acima do nível do mar. Em função da altitude e da umidade causada pela proximidade do litoral, a vegetação que domina as nascentes desses mananciais é a vegetação de Campos de Altitude, que se desenvolve sobre solos litólicos e turfeiras.

Turfeiras são unidades do relevo, caracterizadas por depressão topográfica isolada ou conectada à rede hidrográfica, nas quais se acumulam depósitos orgânicos (turfas), em ambiente anóxico. Esses depósitos são reconhecidos tanto como importantes poços de retenção de carbono quanto como recipientes de arquivos naturais e de aqüíferos superficiais (THOMPSON et al., 1995). As turfeiras do parque são classificadas como turfeiras de planalto e observações preliminares indicam a existência de turfas ombrotróficas e minerotróficas, de acordo com tipologia proposta por Franchi et al. (2006). Provavelmente, há na área de estudo predomínio de turfeiras ombrotróficas, com desenvolvimento de espessas coberturas de sphagnum (Figura 2).

Através deste trabalho, estamos aplicando metodologia para a valorização abiótica dessas formas de relevo, turfeiras de planalto, que são aqui consideradas como importantes sítios geomorfológicos no interior do Parque Estadual da Serra do Tabuleiro (PEST). 


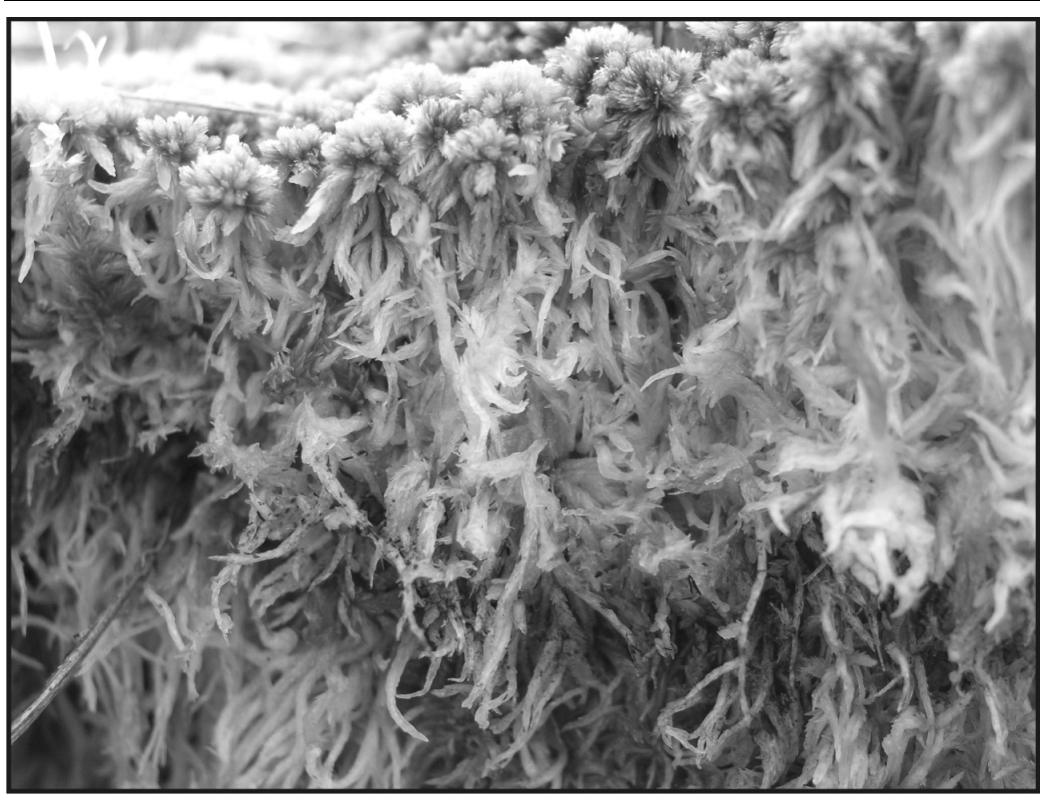

Figura 2: Detalhe de cobertura espessa $(>60 \mathrm{~cm})$ de sphagnum exposta em turfeira em domo nas chapadas da Serra do Tabuleiro. Notar o emaranhado de rizóides alongados característicos dessas briófitas. Foto: Hermann Behling.

\section{Metodologia}

As turfeiras as áreas de topo do PEST vêm sendo estudadas desde 2002, em função de seu potencial para fornecer dados representativos (proxy data) para estudos de reconstituição paleoambiental. Amostras têm sido coletadas para estudos palinológicos (BEHLING et al., 2007) e fatores geomorfológicos relacionados à evolução do relevo local têm sido observados e cadastrados (PAULINO, 2005; OLIVEIRA et al., 2006; DUZZIONI, 2007).

Neste trabalho, aplicamos a um dos setores do parque metodologia adaptada de Pralong (2005) para a avaliação de geomorfosítios. Sítios de interesse geomorfológico foram 
OLIVEIRA, M.A.T. de \& LIMA, G.L. de. Avaliação de geomorfosítios e ...

cadastrados e seus valores científico e paisagístico foram avaliados. Tal como aplicado neste trabalho, o método consiste na definição de pesos específicos para parâmetros científicos e cênicos que são considerados relevantes para a avaliação dos sítios. Outros parâmetros do método original, relacionados ao uso do espaço, não foram adotados. Uma escala de pontuação de 0 a 1 é estabelecida, por exemplo, a intervalos de $1 / 4$ de unidade para cada parâmetro (PRALONG, 2005), gerando "notas" com valores de 0,$0 ; 0,25 ; 0,50 ; 0,75 ; 1,00$, por exemplo, que são atribuídas aos parâmetros avaliados. Os parâmetros considerados foram os que são enumerados a seguir, em função dos valores em foco, a saber, valores científico e cênico:

A) Parâmetros relacionados ao Valor Científico:

A.1 - Interesse paleogeográfico: depende do interesse paleogeográfico do sítio como testemunho para a reconstituição da evolução ambiental da área. Esse parâmetro foi avaliado com o auxílio da medição da profundidade dos depósitos orgânicos na área amostrada (PAULINO, 2005), em associação com a área das turfeiras, estabelecendo classes estatísticas, subdivididas em 4 intervalos, aos quais se atribuiu uma das "notas" acima mencionadas, de 0,0 a 1,0 (OLIVEIRA et al., 2006).

A.2 - Representatividade: depende das características didáticas e exemplares do sítio para assimilação de conteúdo geomorfológico por leigos em Geomorfologia. A leitura é feita com base nos próprios atributos do sítio.

A.3 - Área (\%): a pontuação é calculada pela área $\left(\mathrm{m}^{2}\right)$ do sítio, dividida pela área total ocupada por sítios similares na área do estudo, segundo a equação $A_{S} \cdot A_{T}^{-1}$. 100. Onde $A_{S}$ : área do sítio específico; $\mathrm{A}_{\mathrm{T}}$ : somatório das áreas de todos os sítios similares mapeados.

A.4 - Raridade: a pontuação é calculada em função do número de sítios de área equivalente a do sítio específico avaliado, tal como definido no item anterior. Quanto menor o número de sítios similares, maior a raridade do sítio. Um sítio raro pode representar condições ambientais distintas das atuais, por exemplo, 
OLIVEIRA, M.A.T. de \& LIMA, G.L. de. Avaliação de geomorfosítios e ...

guardando feições herdadas de processos geomorfológicos pretéritos.

A.5 - Integridade: avaliado em função dos riscos naturais e antrópicos que possam afetar a integridade do sítio, agindo sobre sua evolução e preservação.

A.6 - Interesse ecológico: avaliado em função do interesse (raridade de espécies); da diversidade (número de espécies) e da dinâmica natural da fauna e da flora do sítio (capacidade do ambiente de evoluir naturalmente). No caso, avaliou-se apenas a ocorrência de matinhas ciliares associadas aos campos (diversidade) e o estado de preservação dos sítios abordados.

A pontuação final para o Valor Científico de cada sítio é obtida pela média das "notas" obtidas para cada parâmetro: A. $1+$ A. $2+($ A. $3 \times 0,5)+($ A. $4 \times 0,5)+$ A.5+A.6 / 6. Aos parâmetros A. 3 e A.4 é atribuído $1 / 2$ de seu valor nominal, de modo a evitar redundância que deriva da importância que o fator área tem para a avaliação do valor cênico (ver item B.3).

B) Parâmetros relacionados ao Valor Cênico:

B.1 - Número de pontos de vista: trata do somatório de pontos de vista acessíveis a pé, que oferecem ângulos de observação diferenciados, distantes a menos de $1 \mathrm{~km}$ do sítio avaliado. Quanto maior o número de pontos de vista, maior a pontuação.

B.2 - Distância média relativa dos pontos de vista: corresponde à soma das menores distâncias entre pontos de vista de um mesmo sítio, dividida pelo número de pontos de vista do item anterior.

B.3 - Área $\left(\mathrm{m}^{2}\right)$ : área relativa do sítio avaliado, calculado em função da área total de sítios idênticos na área de estudo (ver item A3).

B.4 - Elevação: altitude relativa do sítio avaliado. A pontuação é definida, novamente, em função da elevação do sítio avaliado em relação aos intervalos de classe definidos para as altitudes de todos os sítios similares mapeados na área de estudo. 
OLIVEIRA, M.A.T. de \& LIMA, G.L. de. Avaliação de geomorfosítios e ...

As elevações foram obtidas durante a etapa de cadastramento, através de GPS portátil Garmin.

B.5 - Contraste de cor do sítio com o seu entorno: considera-se o contraste de cores, em função da ocorrência de cores idênticas, diferentes, ou opostas. Quanto maior a diferença de cores, maior o contraste, podendo ser máximo no caso de cores complementares.

A pontuação final para o Valor Cênico de cada sítio é obtida pela média: B.1+B.2+A.3+B.4+B.5 / 5 .

\section{Resultados e discussões}

A área na qual a metodologia foi aplicada está localizada em chapada dissecada, característica dos setores de topo da Serra do Tabuleiro, em seu setor noroeste (ver Figura 1 e Figura 3). Vinte e uma turfeiras foram mapeadas nesse setor do parque.

Os valores dimensionais e altitudinais medidos para as turfeiras estão enumerados no Quadro 1. A partir desses valores foi realizada classificação, levando à obtenção de quatro classes estatísticas para as altitudes e para as áreas das turfeiras (Quadro 2 e Quadro 3). 
OLIVEIRA, M.A.T. de \& LIMA, G.L. de. Avaliação de geomorfosítios e ...

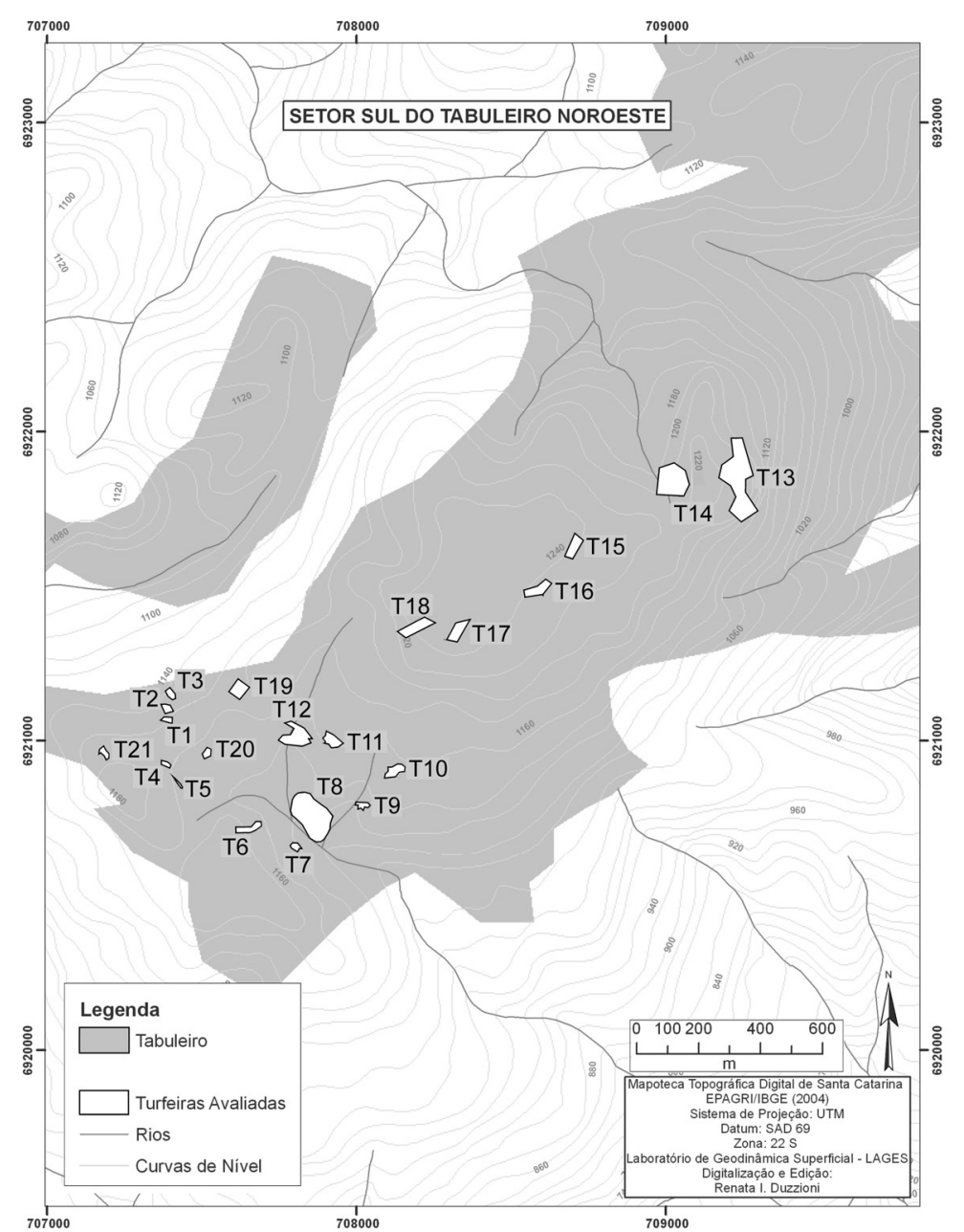

Figura 3: Cartograma de localização dos sítios avaliados. Os números fazem referência às 21 turfeiras consideradas. 
OLIVEIRA, M.A.T. de \& LIMA, G.L. de. Avaliação de geomorfosítios e ...

Quadro 1: Valores de elevação $(\mathrm{m})$ e área $\left(\mathrm{m}^{2}\right)$ dos sítios analisados

\begin{tabular}{|c|c|c|}
\hline Turfeiras & Área $\left(m^{2}\right)$ & Elevação (m) \\
\hline $\mathrm{T}-1$ & 438,55 & 1.145 \\
\hline $\mathrm{T}-2$ & 697,57 & 1.155 \\
\hline $\mathrm{T}-3$ & 690,21 & 1.158 \\
\hline $\mathrm{T}-4$ & 385,57 & 1.170 \\
\hline $\mathrm{T}-5$ & 173.66 & 1.169 \\
\hline $\mathrm{T}-6$ & $1.431,93$ & 1.137 \\
\hline $\mathrm{T}-7$ & 585,72 & 1.124 \\
\hline $\mathrm{T}-8$ & $13.334,23$ & 1.132 \\
\hline T-9 & 645,81 & 1.146 \\
\hline $\mathrm{T}-10$ & $1.687,99$ & 1.137 \\
\hline $\mathrm{T}-11$ & $1.826,42$ & 1.147 \\
\hline $\mathrm{T}-12$ & 4.871 & 1.160 \\
\hline $\mathrm{T}-13$ & $16.340,43$ & 1.221 \\
\hline $\mathrm{T}-14$ & $8.824,72$ & 1.195 \\
\hline $\mathrm{T}-15$ & $2.434,08$ & 1.252 \\
\hline T-16 & $2.415,88$ & 1.247 \\
\hline $\mathrm{T}-17$ & $2.508,31$ & 1.245 \\
\hline T-18 & $3.233,19$ & 1.221 \\
\hline T-19 & $2.216,32$ & 1.179 \\
\hline $\mathrm{T}-20$ & 596,02 & 1.204 \\
\hline $\mathrm{T}-21$ & 616,62 & 1.183 \\
\hline
\end{tabular}

Quadro 2: Classificação para as áreas dos sítios analisados

\begin{tabular}{|c|c|c|}
\hline Classificação & Classe Estatística $\mathbf{( m}^{\mathbf{2}} \mathbf{)}$ & Freqüência Simples \\
\hline Pequena & $173,66-4.215,37$ & 17 \\
\hline Moderada & $4.215,38-8.257,04$ & 2 \\
\hline Grande & $8.257,05-12.298,73$ & 0 \\
\hline Muito Grande & $12.298,74-16.340,42$ & 2 \\
\hline
\end{tabular}

Quadro 3: Classificação para as elevações dos sítios analisados

\begin{tabular}{|c|c|c|}
\hline Classificação & Classe Estatística (m) & Freqüência Simples \\
\hline Baixa & $1.124-1.156$ & 8 \\
\hline Moderada & $1.156-1.188$ & 6 \\
\hline Alta & $1.188-1.220$ & 2 \\
\hline Muito Alta & $1.220-1.252$ & 5 \\
\hline
\end{tabular}


OLIVEIRA, M.A.T. de \& LIMA, G.L. de. Avaliação de geomorfosítios e ...

Pelos quadros acima, deduz-se que $38 \%$ das turfeiras avaliadas ocupam elevações relativamente baixas nas chapadas da Serra do Tabuleiro (abaixo de $1.156 \mathrm{~m}$ ), enquanto $23 \%$ ocupam as altitudes mais elevadas (acima de $1.220 \mathrm{~m}$ ). No que diz respeito às áreas ocupadas pelas turfeiras, $80 \%$ são classificadas como pequenas (menores que $4.200 \mathrm{~m}^{2}$ ) e apenas $9,5 \%$ são classificadas como muito extensas (maiores que $12.300 \mathrm{~m}^{2}$ ). O Quadro 4 ilustra os valores médios obtidos, após avaliação dos critérios científicos e cênicos. Segundo esses valores, pode-se verificar que o valor médio obtido para as 21 turfeiras analisadas na área é 0,35 , sendo o respectivo desvio padrão 0,15 .

Quadro 4: Valor médio dos 21 sítios avaliados, obtido através da média dos valores científico e cênico finais.

\begin{tabular}{|c|c|}
\hline Turfeira & Valor Médio \\
\hline T1 & 0,22 \\
\hline T2 & 0,22 \\
\hline T3 & 0,24 \\
\hline T4 & 0,34 \\
\hline T5 & 0,34 \\
\hline T6 & 0,32 \\
\hline T7 & 0,26 \\
\hline T8 & 0,71 \\
\hline T9 & 0,17 \\
\hline T10 & 0,28 \\
\hline T11 & 0,38 \\
\hline T12 & 0,54 \\
\hline T13 & 0,71 \\
\hline T14 & 0,61 \\
\hline T15 & 0,30 \\
\hline T16 & 0,30 \\
\hline T17 & 0,30 \\
\hline T18 & 0,30 \\
\hline T19 & 0,33 \\
\hline T20 & 0,26 \\
\hline T21 & 0,27 \\
\hline
\end{tabular}


OLIVEIRA, M.A.T. de \& LIMA, G.L. de. Avaliação de geomorfosítios e ...

Observa-se que apenas 4 sítios (T8, T12, T13 e T14) totalizam valores acima da média geral, adicionada ao desvio padrão $(>0,45)$, podendo ser considerados como sítios de valor excepcionalmente elevado, do ponto de vista estatístico. Cinco sítios podem ser classificados como de valor médio (T4, T5, T6, T11 e T19); onze sítios possuem valor inferior ao valor médio, embora ainda dentro do desvio padrão (T1, T2, T3, T7, T10, T15, T16, T17, T18, T20 e T21), e apenas um sítio (T9) tem valor inferior ao valor mínimo estabelecido pelo desvio padrão $(<0,20)$. Consequentemente, do ponto de vista do processo de valoração utilizado, os sítios avaliados podem ser considerados como de valor médio a elevado.

Como pode ser observado no Quadro 1, os sítios qualificados como de valor estatístico excepcional são justamente os que possuem maiores áreas. Como turfeiras maiores tenderiam, em princípio, a serem mais importantes do ponto de vista ambiental (maiores volumes de carbono e de água retidos), a valoração obtida parece coerente. Os quatro sítios considerados estatisticamente excepcionais foram selecionados para avaliação mais detalhada do método aplicado.

O Quadro 5 traz a pontuação obtida para cada um dos parâmetros que são necessários à avaliação dos valores científico e cênico desses quatro sítios (T8, T12, T13, T14). 
OLIVEIRA, M.A.T. de \& LIMA, G.L. de. Avaliação de geomorfosítios e ...

Quadro 5: Pontuação obtida para os quatro sítios melhor avaliados (T8, T12, T13 e T14).

\begin{tabular}{|l|c|c|c|c|}
\hline \multicolumn{1}{|c|}{ Critério avaliado } & $\begin{array}{c}\text { T8 } \\
\text { Pontuação }\end{array}$ & $\begin{array}{c}\text { T12 } \\
\text { Pontuação }\end{array}$ & $\begin{array}{c}\text { T13 } \\
\text { Pontuação }\end{array}$ & $\begin{array}{c}\text { T14 } \\
\text { Pontuação }\end{array}$ \\
\hline A1 - Interesse Paleogeográfico & 1,00 & 0,75 & 0,75 & 0,75 \\
\hline A2 - Representatividade & 1,00 & 0,75 & 1,00 & 0,75 \\
\hline A3 - Área & $0,38^{*}$ & $0,25^{*}$ & $0,38^{*}$ & $0,25^{*}$ \\
\hline A4 - Raridade & $0,50^{*}$ & $0,50^{*}$ & $0,38^{*}$ & $0,38^{*}$ \\
\hline A5 - Integridade & 1,00 & 0,75 & 0,75 & 0,75 \\
\hline A6 - Interesse Ecológico & 0,75 & 0,50 & 0,50 & 0,50 \\
\hline Pontuação Total & 4,63 & 3,50 & 4,00 & 3,38 \\
\hline Valor Científico & $\mathbf{0 , 7 7}$ & $\mathbf{0 , 5 8}$ & $\mathbf{0 , 6 7}$ & $\mathbf{0 , 5 6}$ \\
\hline B1 - Pontos de Vista & 1,00 & 0,50 & 0,75 & 0,75 \\
\hline B2 - Distância Pontos de Vista & 0,50 & 0,50 & 0,50 & 0,50 \\
\hline B3 - Superfície & 1,00 & 0,50 & 1,00 & 0,75 \\
\hline B4 - Elevação & 0,25 & 0,50 & 1,00 & 0,75 \\
\hline B5 - Contrastes & 0,50 & 0,50 & 0,50 & 0,50 \\
\hline Pontuação Total & 3,25 & 2,50 & 3,75 & 3,25 \\
\hline Valor Cênico & $\mathbf{0 , 6 5}$ & $\mathbf{0 , 5 0}$ & $\mathbf{0 , 7 5}$ & $\mathbf{0 , 6 5}$ \\
\hline Valor Médio & $\mathbf{0 , 7 1}$ & $\mathbf{0 , 5 4}$ & $\mathbf{0 , 7 1}$ & $\mathbf{0 , 6 1}$ \\
\hline
\end{tabular}

* Valores multiplicados por 0,5 para reduzir a redundância do parâmetro dimensional.

A turfeira T8 se situa em local de grande beleza cênica, no interior de alvéolo, cujas águas drenam para o vale do Rio da Vargem do Braço (Figura 4). 


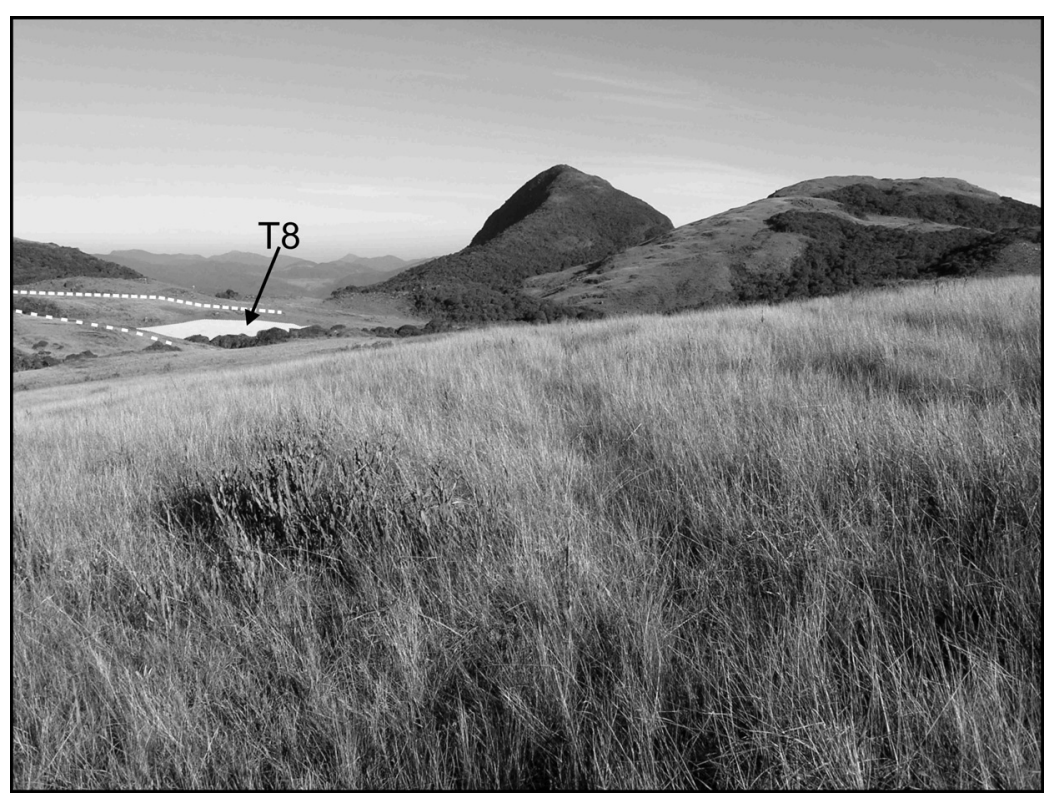

Figura 4: Contexto geral do sítio da turfeira T8. Notar domo rochoso ao fundo. Ocorrem no local patamares topográficos (remanescentes de pedimento). A localização da turfeira é indicada pela seta. Foto: Hermann Behling.

A turfeira T12 faz parte do mesmo alvéolo, embora esteja associada à rampa coluvial, sobre a qual se desenvolve. A turfeira T13 se encontra, igualmente, em local de grande beleza cênica, nas proximidades de "mirante" natural visitado por montanhistas que freqüentam o parque (Figura 5). A turfeira pode ser caracterizada como do tipo "turfeira em domo", característica de turfeiras de planalto ombrotróficas (FRANCHI et al., 2006). A turfeira T14 se desenvolve em cabeceira de vale e atua como zona de contribuição para canal de primeira ordem que surge da turfeira e drena para o rio Cubatão. 


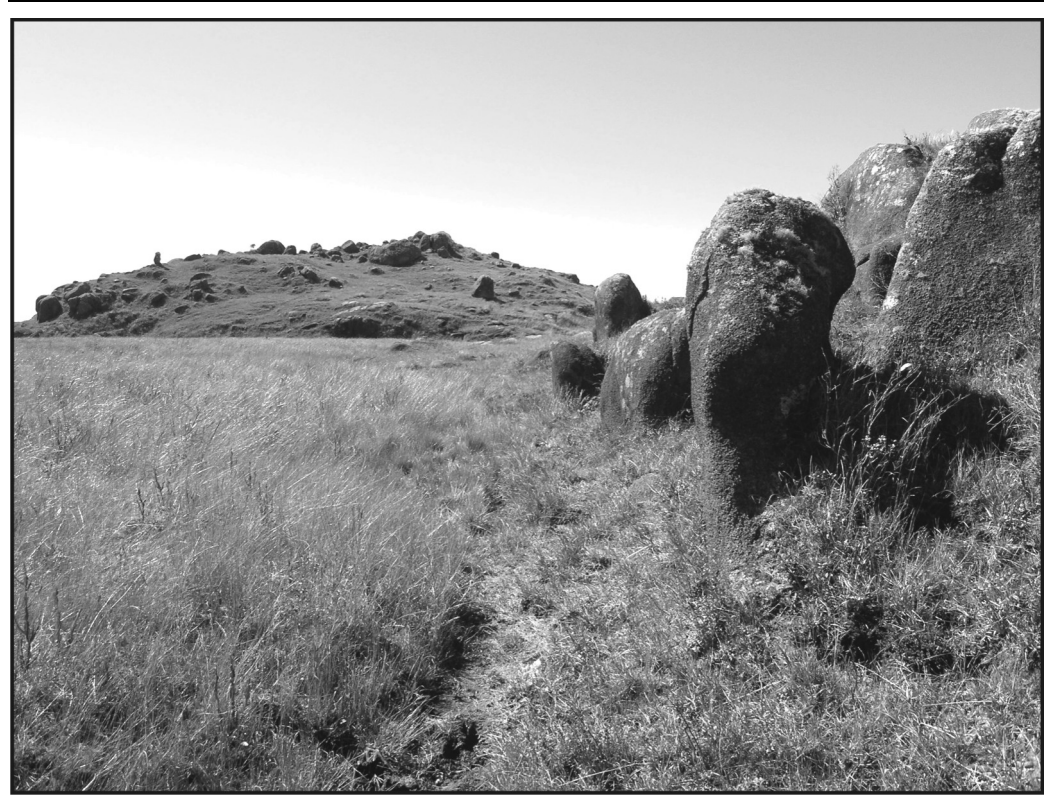

Figura 5: Detalhe da cabeceira da turfeira T13. Notar, em primeiro plano, pilares rochosos (tors) e superfície da turfeira, à esquerda, coberta por gramíneas dos Campos de Altitude. Ao fundo, campo de matacões sobre pequena colina convexa.

Segundo a metodologia adotada, a turfeira T8 possui maior valor científico, sendo a segunda em valor cênico. A turfeira T13 é a que possui maior valor cênico, sob forte influência de sua classe altitudinal (elevação). No conjunto, essas duas turfeiras obtiveram valor final idêntico, embora em função de parâmetros distintos (Quadro 5). A turfeira T13 se encontra em sítio que, apesar da elevada beleza cênica e elevado potencial científico, é menos expressivo do ponto de vista geomorfológico do que o sítio da turfeira T8. De fato, o sítio da turfeira T8 abriga grande número de feições geomorfológicas, como remanescentes de pedimento erosivo (Figura 6), rampas coluviais, terraço aluvial, domo rochoso 
OLIVEIRA, M.A.T. de \& LIMA, G.L. de. Avaliação de geomorfosítios e ...

e provável turfeira em domo. A turfeira T13 está situada em depressão topográfica pouco escavada, cercada por blocos exumados de granito que, apesar de algumas feições curiosas (Figura 5), são muito comuns aos campos de matacões que caracterizam a maioria dos terrenos esculpidos sobre rochas cristalinas. O mesmo pode ser dito da turfeira T14 no que diz respeito às formas de relevo, embora o sítio apresente configuração típica de cabeceira de vale e constitua zona de alimentação para canal de primeira ordem. A turfeira T12 possui interesse específico na medida em que a turfa se desenvolve em encosta coluvial, com conseqüências sobre a qualidade e tipologia da turfa.

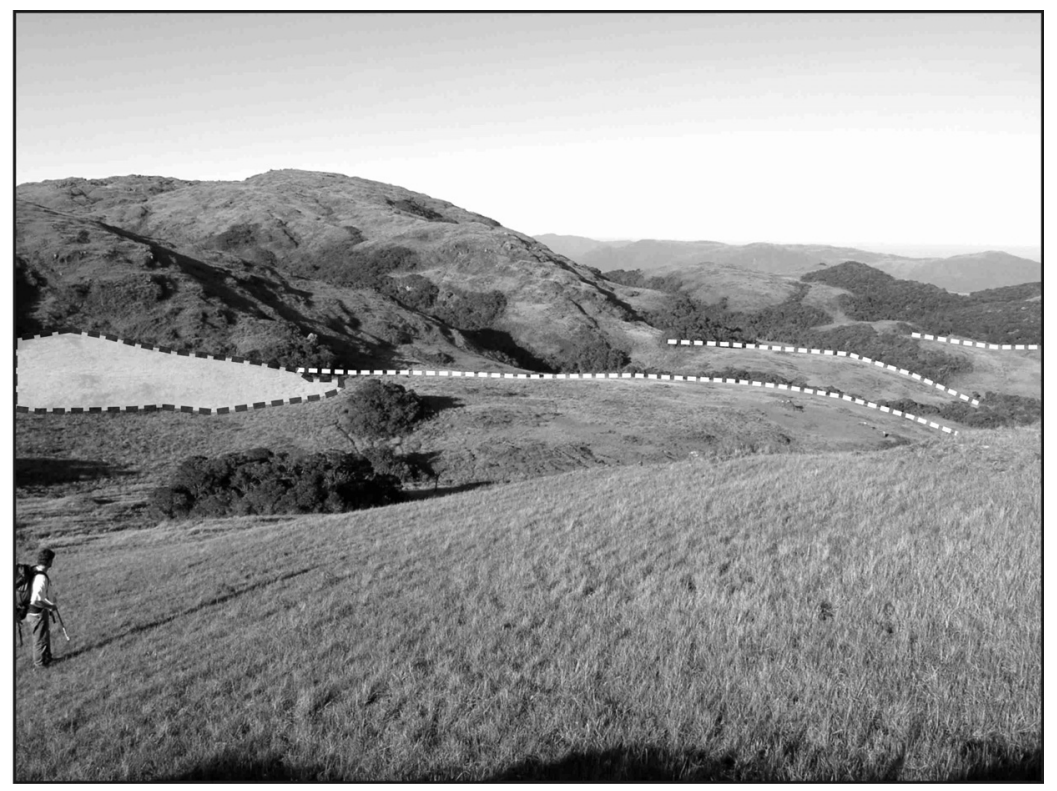

Figura 6: Remanescentes de superfície geomorfológica (pedimento erosivo), realçados por linha tracejada, no interior do alvéolo do sítio T8. Notar rampa coluvial, ressaltada por transparência à esquerda da foto, sobre pedimento. 
OLIVEIRA, M.A.T. de \& LIMA, G.L. de. Avaliação de geomorfosítios e ...

Do ponto de vista da avaliação da aplicação do método aos sítios do estudo, surpreende um pouco o fato de a turfeira T13 ter o mesmo valor final que a turfeira $\mathrm{T} 8$, apesar do potencial relativamente elevado das turfeiras analisadas para a obtenção de dados representativos de mudanças ambientais do Quaternário (BEHLING et al., 2007). De fato, a turfeira T13 ilustraria processos geomorfológicos relacionados, sobretudo, ao intemperismo e à exumação de rochas graníticas em clima temperado úmido. Já a turfeira T8, além de ilustrar os mesmos processos, inclusive com a individualização de domo rochoso (Pão de Açúcar), tem ainda sua evolução e localização associadas à abertura de alvéolo intermontano; à formação de níveis pedimentares; à deposição de rampas coluviais e de terraço aluvial, representando feições de relevo que ocupam posição central no que pode ser considerada a teoria geomorfológica mais longeva da história da Geomorfologia brasileira (BIGARELLA et al., 1965). Seu interesse, enquanto geomorfosítio é, conseqüentemente, superior ao do sítio T13, e a dos demais sítios avaliados.

Apesar dessa ressalva, o resultado obtido reflete fielmente a metodologia utilizada (PRALONG, 2005). O método aplicado tem, originalmente, o objetivo de avaliar geomorfosítios para o eventual uso turístico. Como esse uso é, em tese, relativamente restrito nas unidades de conservação brasileiras, os resultados obtidos enfatizaram apenas o valor científico e cênico dos sítios estudados. Esses valores seriam, em princípio, os mais apreciados para efeitos de individualização de monumentos naturais e, consequentemente, para a definição de áreas passíveis de proteção especial no PEST, podendo, desta feita, auxiliar a elaboração de seu plano de manejo.

\section{Valoração de sítios geomorfológicos: formação do profissional avaliador e aplicação a unidades de conservação}

Os resultados acima demonstram a aplicação de metodologia que fornece às formas de relevo valores específicos. Segundo Prandini e Nakasawa (1994) o ambiente natural, visto enquanto bem comum que possui valor de uso, deve ser avaliado em função 
OLIVEIRA, M.A.T. de \& LIMA, G.L. de. Avaliação de geomorfosítios e ...

das expectativas da sociedade em relação ao seu habitat. Para que essas expectativas possam encontrar expressão é necessária a criação de mecanismos de atribuição de valor a sítios que possam, justamente, constituir o habitat. Como as formas de relevo podem ser consideradas como interfaces nas quais atuam múltiplos agentes evolutivos (REYNARD \& PANIZZA, 2005), suas características morfoestruturais e morfodinâmicas são fundamentais para a atribuição de valor de uso ao território que será ocupado e modificado (OLIVEIRA \& HERMANN, 2006).

Para Moraes (1999), o valor de um lugar poderia ser avaliado através dos conceitos de valor contido e de valor criado. $\mathrm{O}$ primeiro conceito é definido pelas vantagens comparativas apresentadas pelos lugares. O segundo decorre da valoração (ato de atribuir valor qualitativo ou quantitativo) dos lugares, criando valores de uso, de renda e de lucro. O conceito de valor contido implica o reconhecimento da vocação de um lugar em função do seu valor potencial, como no caso da valoração de espaços preservados e monumentos naturais que constituem, de fato, uma reserva de valor. Já o conceito de valor criado implica o reconhecimento de recursos naturais e sua transformação em produtos. Nesse sentido, o processo de valoração do espaço físico deveria ser o vetor através do qual suas possibilidades e limitações de exploração seriam definidas, em função do potencial de valor neles identificado (OLIVEIRA \& HERMANN, 2006). O processo de valoração de um sítio deveria definir suas prioridades de uso e, portanto, seu microzoneamento (MORAES, 1999).

Essa discussão, sobre atribuição de valor e planejamento (MORAES, 1999), pode ser complementada pelo debate em torno do conceito de geomorfosítio, tal como definido anteriormente, através do qual atribui-se valor às formas de relevo em função de motivos científicos, culturais, estéticos e/ou sócio-econômicos (PANIZZA, 2001). Inserida na perspectiva do planejamento, a aplicação do método de valoração de geomorfosítios ilustra claramente processo através do qual as formas de relevo assumem papel central na percepção do ambiente natural e na sua 
OLIVEIRA, M.A.T. de \& LIMA, G.L. de. Avaliação de geomorfosítios e ...

apropriação. Trata-se, de fato, de metodologia integradora que aborda com simplicidade o problema da relação entre a sociedade e a natureza, através da definição e da quantificação de valores contidos (valores científico e cênico) e de valores de uso (valor estético, cultural, ecológico, econômico) de sítios geomorfológicos.

No entanto, o processo de valoração de geomorfosítios não deve ser aplicado mecanicamente, e requer avaliação crítica dos resultados obtidos. De fato, em estudo no qual sítios geomorfológicos italianos foram avaliados por geomorfólogos com diferentes especialidades, Bruschi e Cendrero (2005) observam que, apesar da obtenção de resultados de valoração globalmente consistentes, algumas incongruências foram introduzidas no processo, justamente em função do que cada especialista consideraria ser o mais importante a ser ressaltado. Essa é uma observação relevante, no atual estágio de desenvolvimento da Geomorfologia, pois coloca em evidência dois atributos que, em nossa opinião, são fundamentais para a capacitação de bons avaliadores de sítios geomorfológicos: a) a formação ampla em geomorfologia; b) a ausência de preconceito teórico-conceitual.

Com efeito, tal como exemplificado pelos resultados obtidos neste estudo, formas de relevo clássicas da geomorfologia brasileira, associadas à chamada teoria da pedimentação (BIGARELLA et al. 1965), cuja generalização tem sido questionada (PEULVAST \& CLAUDINO-SALES, 2004; SALLUN \& SUGUIO, 2006), foram identificadas nas chapadas da Serra do Tabuleiro (pedimentos, rampas e terraços). É nesse sentido que ressaltamos a necessidade da formação geomorfológica ampla de profissionais avaliadores de geomorfosítios, que devem estar preparados para contemplar tanto conceitos geomorfológicos de ponta quanto teorias e conceitos clássicos, além de seus aspectos técnicos.

Esforços sistemáticos voltados para a preservação da memória da Terra têm sido efetuados no Brasil através da definição e individualização de monumentos naturais, desde a década de 1990. Destacam-se nesse processo a criação da SIGEP (Comissão 
OLIVEIRA, M.A.T. de \& LIMA, G.L. de. Avaliação de geomorfosítios e ...

Brasileira de Sítios Geológicos e Paleobiológicos - DNPM), o Projeto Geoparques (Serviço Geológico do Brasil - CPRM) e o Projeto Caminhos Geológicos (DRM-RJ). Dessas três iniciativas a SIGEP é a única que abre espaço para a atuação da geomorfologia (WINGE et al., 2004). O Projeto Geoparques (CAMOZZATO, 2004) e o Projeto Caminhos Geológicos (MANSUR \& ERTHAL, 2004), por sua vez, adotam como critério principal aspectos geológicos e cênicos que, embora não excluam a abordagem geomorfológica, são essencialmente os mesmos que fundamentaram a criação dos parques naturais norte-americanos no século XIX, com ênfase em aspectos monumentais.

Além de abrir espaço para a atuação de geomorfólogos no campo da definição e da preservação do patrimônio natural, a abordagem de geomorfosítios transcende a filosofia preservacionista clássica, monumental, abrindo-se para o campo do planejamento e da gestão territorial, através da ênfase dada às formas de relevo como recursos naturais. No que toca à definição de espaços preservados, o processo de avaliação de geomorfosítios deve ser incorporado como metodologia para o encaminhamento de candidaturas de tombamento de sítios geológicos e geomorfológicos, pois oferece critérios objetivos e flexíveis de valoração, centrados tanto no monumental quanto na concepção das formas de relevo enquanto interfaces de agentes múltiplos.

Além disso, o conceito de geomorfosítio permite a valorização de sítios que são importantes para a preservação da história ambiental local, independentemente de sua escala espacial. Com efeito, pequenos afloramentos ou formas de relevo específicas não são prestigiados pelo conceito de Geoparques, por exemplo, que pressupõe a existência de unidades territoriais relativamente extensas, com condições de acesso específicas e com potencial para atrair público permanente. Nesse sentido, pequenos sítios em locais de difícil acesso, como é o caso das turfeiras do Parque Estadual da Serra do Tabuleiro, dificilmente seriam valorizados como unidades do relevo que preservam a memória da Terra e que seriam, portanto, dignos de proteção especial, ou de tombamento. 
OLIVEIRA, M.A.T. de \& LIMA, G.L. de. Avaliação de geomorfosítios e ...

A utilização do conceito de geomorfosítio abre caminhos para a geomorfologia no que refere à definição do patrimônio natural no Brasil, incorporando, sim, a visão clássica da preservação da paisagem agreste (wilderness), fundamentada em monumentos naturais; mas também reivindicando para a Geomorfologia abordagem que permite ampla articulação entre a conservação da história da Terra e a transformação do espaço físico, através da criação de valores de uso.

\section{Conclusões}

Resultados inéditos na área deste estudo apontam para a definição e mapeamento de arquivos históricos naturais (turfeiras), que trazem registros dos efeitos de mudanças climáticas globais do passado sobre a composição da vegetação local. As turfeiras abordadas, além de serem pouco estudadas no Brasil, constituem importantes aqüíferos superficiais, arquivos naturais e sumidouros de carbono que, associados ao relevo e à importância da hidrografia local para o abastecimento da Grande Florianópolis, têm elevados valores científico e social. A aplicação da metodologia desenvolvida para avaliação de geomorfosítios permite mensurar esses valores para a unidade de conservação contemplada. A definição, em si, do conceito de geomorfosítios, coloca em evidência o potencial da Geomorfologia para o estudo das unidades de conservação brasileiras, assim como para fins de planejamento e de gestão territorial.

\section{Agradecimentos}

Este trabalho foi iniciado no contexto da disciplina "GCN 3506 - Tópicos Especiais em UCRN (Geomorfologia em Unidades de Conservação)", ministrada no Programa de Pós-Graduação em Geografia, UFSC, de 2004 a 2006. A incorporação da abordagem de Geomorfosítios à disciplina foi realizada a partir de sugestão do professor Dr. Joel Pellerin, a quem agradecemos pela introdução à metodologia. O cadastramento e classificação preliminar das turfeiras do parque foram realizados com o apoio da FAPESC 
OLIVEIRA, M.A.T. de \& LIMA, G.L. de. Avaliação de geomorfosítios e ...

(convênio: 8057/2004-8) e com o apoio do CNPq (processo: 503846/2004-0), sob anuência da FATMA - Fundação do Meio Ambiente do Estado de Santa Catarina.

\section{Referências bibliográficas}

BEHLING, H.; SAFFORD, H. F.; OLIVEIRA, M. A. T. \& DUPONT, L. M. Late Quaternary vegetation, biodivertsity, fire and climate dynamics in the Atlantic mountain region of eastern Brazil. In: VXII INQUA Congress, 2007, Cairns. Quarternary International, 167-168, p. 30-31.

BIGARELlA, J. J.; MOUSINHO, M. R. \& SILVA, J. X. Pediplanos, pedimentos e seus depósitos correlativos no Brasil. Boletim Paranaense de Geografia, 16/17, p.117-151, 1965.

BRASIL. Lei ${ }^{\circ}$ 9.985, de 18 de julho de 2000. Institui o Sistema Nacional de Unidades de Conservação da Natureza. Brasília: Diário Oficial da União, 19 de julho de 2000, Seção I. 2000.

BRUSCHI, V. M. \& CENDRERO, A. Geosite evaluation; can we measure intangible values? Il Quaternario, 18 (1), p. 293-306. 2005

CAMOZZATO, E. Geoparques - Reservas da Geosfera. XLII Congresso Brasiliero de Geologia, 2004, Araxá - MG, SBG Núcleo Minas Gerais. Anais do... 2004.

DIEGUES, A. C. O mito moderno da natureza intocada. São Paulo, Hucitec, 1996.

DUZZIONI, R. I. Feições erosivas em turfas de topo, nas montanhas do Parque Estadual da Serra do Tabuleiro. Trabalho de Conclusão de Curso. (Graduação em Geografia) Universidade Federal de Santa Catarina, CNPq, 42 p, 2007.

FRANCHI, J. G.; SÍGOLO, J. B. \& MOTTA, J. F. M. Diagnóstico das turfas no Brasil: histórico da utilização, classificação, geologia e dados econômicos. Revista Brasileira de Geociências, 36 (1- Suplemento), p. 179-190. 2006. 
OLIVEIRA, M.A.T. de \& LIMA, G.L. de. Avaliação de geomorfosítios e ...

MANSUR, K. \& ERTHAL, F. O Projeto Caminhos Geológicos e seus Desdobramentos no Estado do Rio de Janeiro. XLII Congresso Brasiliero de Geologia, 2004, Araxá - MG, SBG Núcleo Minas Gerais. Anais do... 2004.

MORAES, A.C.R. Contribuições para a gestão da zona costeira do Brasil. Elementos para uma Geografia do Litoral Brasileiro. Editora Hucitec, São Paulo, 229 p. 1999.

OLIVEIRA, M.A.T. E HERMANN, L.P. Ocupação do solo e riscos ambientais na área conurbada de Florianópolis. In: GUERRA, A.J.T. E CUNHA, S.B. (Orgs.) Impactos ambientais urbanos no Brasil. Bertrand Brasil, Rio de Janeiro, Quarta Edição, p. 147-188. 2006.

OLIVEIRA, M. A. T.; LIMA, G. L.; DUZZIONI; PAULINO, R. B. Avaliação de geomorfosítios e valorização abiótica de unidades de conservação: estudo de caso no Parque Estadual da Serra do Tabuleiro (SC). In: VI Simpósio Nacional de Geomorfologia / Regional Conference on Geomorphology, Anais / Actes, Trabalhos Completos. Goiânia, 2006. v. 2. p. 1-10.

PANIZZA, M. Geomorphosites: concepts, methods and example of geomorphological survey. Chinese Science Bulletin, 46, Suppl. Bd, p. 4-6. 2001.

PAULINO, R. B. Mapeamento e caracterização de turfeiras na Serra do Tabuleiro, Parque Estadual da Serra do Tabuleiro (SC). Trabalho de Conclusão de Curso. (Graduação em Geografia) - Universidade Federal de Santa Catarina, CNPq, 37 p. 2005.

PEULVAST, J. P. ; CLAUDINO-SALES, V. Stepped surfaces and palaeoforms in the northern Brazilian «Nordeste»: constraints on models of morphotectonic evolution. Geomorphology, 62, p. 89-122, 2004.

PRALONG, J.-P. A method for assessing tourist potential and use of geomorphological sites. Géomorphologie: relief, processus, environnement, n. 3, p. 189-196. 2005. 
OLIVEIRA, M.A.T. de \& LIMA, G.L. de. Avaliação de geomorfosítios e ...

PRANDINI, F. L. \& NAKASAWA, V. A. Desafios ambientais da civilização urbana: uma síntese. In: Primeira Oficina se Desenho Urbano de Florianópolis. Universidade Federal de Santa Catarina. Florianópolis. Anais da.... p. 40-43. 1994.

RANDOLPH, R. \& BESSA, E. O meio ambiente como forma específica de organização territorial: elementos para uma discussão conceitual. In: Encontro Nacional da ANPUR, IV. 1991, Salvador, Anais... Salvador: ANPUR; UFBA, p.639-649. 1993.

REYNARD, E. Géomorphosites et paysages. Géomorphologie: relief, processus, environnement, n. 3, p.181-188. 2005.

REYNARD, E.; PANIZZA, M. Geomorphosites: definition, assessment and mapping. An introduction. Géomorphologie: relief, processus, environnement, n. 3, p.177-180. 2005.

SAlluN, A. E. M. \& SUGUIO, K. Depósitos quaternários da região entre Marília e Presidente Prudente (SP). Revista Brasileira de Geociências, vol 36, n. 3, p. 392-402.

THOMPSON, D. B. A..; MACDONALD, A. J.; MARSDEN, J. H. \& GALBRAITH, C. A. Upland heather moorland in Great Britain: a review of international importance, vegetation changes and some objectives for nature conservation.

Biological Conservation, 71, p. 163-78. 1995.

UNESCO. Declaração Internacional dos Direitos à Memória da Terra. In: Primeiro Simpósio Internacional sobre a Proteção do Patrimônio Geológico. Digne-Les-Bains, França, 2001.

WINGE, M.; SCHOBBENHAUS, C., CAMPOS, D. A.; QUEIROZ, E. T. \& BERBERT-BORN, M.L. (2004) A SIGEP e suas perspectivas no Brasil. XLII Congresso Brasiliero de Geologia, 2004, Araxá - MG, SBG - Núcleo Minas Gerais. Anais do... 2004. 